\title{
Prerequisites for creating a bucket to improve the quality of selective coal mining
}

\author{
Elena Zelayeva ${ }^{1 *}$, Vyacheslav Venger $^{1}$, and Jaynangul Khammetova ${ }^{2}$ \\ ${ }^{1}$ Branch of T.F. Gorbachev Kuzbass State Technical University in Prokopievsk, 653039, 19a \\ Nogradskaya str., Prokopievsk, Kemerovo region, Russian Federation \\ ${ }^{2}$ Ekibastuz Engineering Technical Institute named after academic K. Satpayev, 141208, 54a \\ Energetics St., Ekibastuz, Republic of Khasakstan
}

\begin{abstract}
Ensuring the improvement of the quality of the extracted coal is one of the most important tasks for improving the efficiency of the enterprise as a whole. A significant role in the extraction of minerals is played by the choice of equipment with the right characteristics, since the quality of coal products is formed not only from the natural (mining and geological) conditions of the formation. The article considers one of the main prerequisites for creating a bucket with rational parameters to improve the quality of selective excavation.
\end{abstract}

\section{Introduction}

Maintaining rational indicators of coal quality and consumer requirements is one of the most important tasks of modern mechanized coal mining. An important aspect is the completeness of the extraction of the fossil at various stages of the development of the field. The quality of the extracted coal and its cost are directly dependent on the applied technological means and methods of extracting the mineral, the equipment used (mining machines), as well as the methodological study of the issues of rationing losses.

\section{Formulation of the problem}

The economic performance of the enterprise depends on the equipment used and the production technology. Technologies and typical technological schemes of selective mining are considered in great detail in works [1,2]. Improving the efficiency of mining operations can be achieved by using complex methods using new materials and survey methods described in $[3,4,5,6,7]$.

When mining seams of a complex structure, in order to reduce losses, to improve the quality of coal, excavators with a relatively small bucket capacity are used, for which special excavation technological schemes are developed.

The discrepancy between the parameters of the working equipment used and the reservoir capacity entails a number of negative consequences: loss of the quality of the

* Corresponding author: zelayevaea@yandex.ru 
mineral (dilution), an increase in coal losses due to the leaving of "shortage" prisms under high ledges, ...

The performance of the excavator, with selective excavation, depends on the power of the applied rock layer and the angle of rotation of the excavator when scooping. Reducing these parameters leads to a decrease in the productivity of the equipment by reducing the bucket filling volume or increasing the excavation cycle, but reduces the loss and dilution of the extracted coal. Therefore, the choice of the main parameters of both the equipment and the technology should be such that the decrease in the performance of the equipment is compensated by obtaining better products.

\section{Research result}

The increase in the volume of overburden operations in the mining industry necessitates the creation of both new highly efficient excavating equipment and its individual components that provide an increase in economic indicators [8].

The working equipment, in particular the buckets of hydraulic excavators, experience heavy loads, since they have direct contact with the excavated masses. To improve the quality of work, it requires an understanding of the physical processes of digging, as well as the forces acting on the bucket from the ground and the counteracting forces from the working equipment.

It is known that during the introduction of the bucket into the ground, it is affected by: the force on the cutting edge of the tooth; the force of friction of the tooth on the ground; the force of the soil on the bucket wall; the force of friction of the bucket wall on the ground; the force of resistance to the destruction of the soil layers; the reaction of the forces of the soil on the ground when the layer is shifted, the force of adhesion of particles between the soil layers[9, 10, 11, 12].

To ensure effective extraction of minerals, it is necessary to use a bucket with correctly selected parameters that have an adjustable scooping trajectory.

In the work of D. I. Fedorov [13], the movement of the working bodies of single-bucket excavators with a straight and reverse shovel occurs along curved trajectories of various types. In practice, when scooping rock mass, the actual trajectories have deviations from the theoretical ones, due to both the mining and geological features of the formation structure and kinematic features.

A lot of work is devoted to the quality control of the extracted mineral with the help of excavators based on the use of various sensors [14]. Popov G. N. in his work [15], considered the quality control of rock mass with the help of sensors installed on the excavator bucket, with sequential batch excavation, with separate extraction by a singlebucket excavator. With this method, information about the quality of the rock mass in the bucket is recorded at the end of the single scooping process, when the loss of quality indicators of the mineral during scooping has already occurred.

Analysis of the coal seams of Kuzbass shows that the structure is $70 \%$ complex. When excavating such layers, the technology should be based on the knowledge of the regularities of the formation of the quality of the extracted coal. The inconsistency of the used excavation equipment (individual units) with the mining and geological conditions of the occurrence of coal seams is one of the most pressing issues today.

The dynamics of the main indicators of the quality of extracted coal indicates a continuous increase in production volumes and a simultaneous deterioration in the quality of the extracted mineral. The separation of complex layers into coal bundles and rock layers, during their excavation by an excavator, leads to a significant decrease in its productivity. Therefore, the actual performance of the excavator under various schemes of its application is one of the main indicators of the efficiency of the scheme used. 
In research, the results of modeling the working equipment of the excavator are often used, analyzing the overall performance of the work $[16,17,18]$.

Given all of the above, one of the solutions to the above question, it is proposed to consider-the selection of rational parameters of the working equipment (bucket) by modeling, for specific mining and geological conditions.

This is the prerequisite for creating a bucket of a hydraulic excavator used for selective excavation of coal seams, in order to maintain rational indicators of coal quality, and determines the relevance and significance of this research area for the mining industry.

\section{Conclusion}

Currently, special attention is paid to improving the quality of the extracted products. The complexity of mineral extraction directly depends on the mining and geological features of the occurrence, the structure of coal seams, as well as changes in the wide range of angles of incidence and power. The use of existing methods and means is not always advisable, due to the high level of mineral losses and the low quality of the extracted coal.

For efficient mining, it is necessary to use properly selected equipment and technology that ensures high-quality coal extraction with high equipment productivity.

\section{References}

1. A.E. Antipov, E.B. Vagin, V.P. Bortnikov, Typical technological schemes of mining operations at coal mines (Nedra, Moscow, 1980)

2. A.S., Tashkinov V.G. Pronoza, Album of typical technological schemes for conducting mining operations in the construction of coal mines for various mining and geological conditions (Kuzniishakhtstroy, Kemerovo, 1984)

3. E. Pudov, E. Kuzin, A. Efremenkov, et al., IOP Conf. Ser.: Mater. Sci. Eng., 253, 012063 (2020)

4. M. Mamaeva, E. Kuzin E., MATEC Web of Conferences, 297, 03006 (2019)

5. B. Gerike, I. Panachev, E. Kuzin, E3S Web of Conferences, 15, 03008 (2017)

6. D. Lubyanoi, E. Pudov, E. Kuzin, O. Semenova, R. Rybár, E3S Web Of Conferences, 242, 03022 (2020)

7. E. Kuzin, M. Mamaeva, B. Gerike, K. Singh, E3S Web Of Conferences IVth International Innovative Mining Symposium, 209, 03011 (2019)

8. V.S. Velikanov, M.Yu. Gurov, The development of scientific and methodological foundations for improving mining excavators based on a fuzzy-multiple approach: Monograph (Magnitogorskii gosudarstvennyi tekhnicheskii universitet im.G.I.Nosova, Magnitogorsk, 2018)

9. V.N. Tarasov, M.V. Kovalenko, Construction and road vehicles, 7 (2003)

10. V.N. Kuznetsova, V.V. Savinkin, Construction and road vehicles, 3 (2015)

11. V.N. Kuznetsova, V.V. Savinkin, V.G. Yakovlev, Investigation of the influence of the inertial load of the excavator working equipment on the formation of stress concentrations in its elements, 5 (2015)

12. V. Velikanov, Journal of Mining Institute, 241 (2020)

13. D.I. Fedorov, Working bodies of earthmoving machines (Mashinostroenie, Moscow, 1977) 
14. F.N. Salov, V.I. Ermolaev, I.P. Semin, Vladimir Kryuchkov, V.A. Viktorenko, E.G., Artemyev, A.M. Galkin, A.D. Lensky, V.M. Stolyarov, and.with. USSR №750531

15. G.N. Popov, Development of deposits of radioactive ores (Atomizdat, Moscow, 1970)

16. V.G Ananin, Bulletin of the Tomsk State University of Architecture and Civil Engineering, 1, 38, 5 (2013)

17. V.N., Kuznetsova, V.V. Savinkin, Vestnik SibADI, 6(40), 26 (2014)

18. V.P. Pavlov, A.N. Abramov, Transport construction, 7 (1984) 